\title{
A CLINICAL STUDY ON CUTANEOUS ADVERSE DRUG REACTIONS
}

\author{
Lakshmi Asokan¹, K. Abdul Samad², Joan Felicita Samson ${ }^{3}$
}

1 Junior Resident, Department of Dermatology and Venereology, Government Medical College, Trivandrum, Kerala.

${ }^{2}$ Additional Professor, Department of Dermatology and Venereology, Government Medical College, Trivandrum, Kerala.

${ }^{3}$ Professor, Department of Dermatology and Venereology, Dr. Somervell Memorial CSI Medical College, Karakonam, Trivandrum.

\section{ABSTRACT}

\section{BACKGROUND}

Adverse drug reactions (ADR) are a legacy of the rapid and newer developments made in the field of pharmaceuticals worldwide every day. They represent an important but underestimated cause of morbidity, increased health expenditure, hospital admissions and even mortality.

This study focuses on the various morphological patterns of cutaneous ADR, the causative drugs and the outcome of the reactions. It also aims to find out the probable causative drugs using an in vivo test in the form of patch test.

\section{MATERIALS AND METHODS}

This is a descriptive study undertaken in the Department of Dermatology and Venereology, Medical College Hospital, Thiruvananthapuram, South India for a period of one year, which included 121 clinically diagnosed cases of cutaneous adverse drug reactions.

\section{RESULTS}

92 of them presented with complaints of skin lesions (96.7\%); 24 patients had taken penicillins (19.8\%) which was the predominant drug; 59 patients (48.8\%) had developed reaction within 3 days of administration of the drug. Erythematous macules, papules and small plaques were noticed in 68 patients $(56.2 \%)$; 43 patients (35.5\%) had associated mucosal lesions with majority having involvement of more than one mucosal site. Patch test was done in 39 patients (32.2\%) and a positive test result was obtained in 12 cases (9.9\%). Exanthematous reactions were observed in 48 patients (39.7\%) and urticaria and angioedema in 34 patients $(28.1 \%)$. There were 18 cases $(14.9 \%)$ in the SJS-TEN complex. Exanthematous reactions were commonly produced by anticonvulsants in 16 patients (33.33\%).

\section{CONCLUSION}

This prospective descriptive study on cutaneous adverse drug reactions in 121 cases showed the commonest pattern of drug reaction being exanthematic type followed by urticaria/angioedema and SJS/TEN complex. The commonest offending drug group was NSAIDS, in which paracetamol and diclofenac were the commonest individual drugs imputed followed by anticonvulsants and antibiotics. Penicillins and cephalosporins were the commonest antibiotics responsible. The previously implicated carbamazepine as the commonest cause for severe cutaneous adverse reactions has been taken over by phenytoin as observed in this study. The in vivo patch test using the suspected offending drug as the antigen was positive in $30.7 \%$ of the tested cases indicating its role as an adjunct to clinical diagnosis as in a few earlier studies.

\section{KEYWORDS}

Adverse Drug Reactions, Exanthematous Reactions, Urticaria/Angioedema, SJS/TEN Complex and Patch Test.

HOW TO CITE THIS ARTICLE: Asokan L, Samad KA, Samson JF. A clinical study on cutaneous adverse drug reactions. J. Evolution Med. Dent. Sci. 2017;6(49):3757-3762, DOI: 10.14260/Jemds/2017/812

\section{BACKGROUND}

The adverse drug reactions are a legacy of the rapid and newer developments made in the field of pharmaceuticals worldwide everyday. ${ }^{1}$ They represent an important but underestimated cause of morbidity, increased health expenditure, hospital admissions and even mortality.,2,3

This study focuses on the various morphological patterns of cutaneous ADR, the causative drugs and the outcome of the reactions. It also aims to find out the probable causative drugs using an in vivo test in the form of patch test.

Financial or Other, Competing Interest: None.

Submission 29-05-2017, Peer Review 09-06-2017,

Acceptance 13-06-2017, Published 19-06-2017.

Corresponding Author:

Dr. Abdul Samad K,

Additional Professor,

Department of Dermatology and Venereology,

Government Medical College,

Trivandrum-695011, Kerala, India

E-mail: drsamad_1961@yahoo.co.in

DOI: $10.14260 /$ jemds $/ 2017 / 812$

\section{Aims of the Study}

1. To study the morphological patterns of adverse drug reactions.

2. To study the probable causative drugs.

\section{MATERIALS AND METHODS}

The study is a descriptive study, which included 121 patients with clinically diagnosed cases of cutaneous adverse drug reactions who attended the OP/IP wing of Department of Dermatology and Venereology, Medical College, Thiruvananthapuram, during the period from January 2012 to December 2012.

\section{RESULTS \\ Gender}

Among the 121 patients in this study, 73 patients $(60.3 \%)$ were females and 48 patients (39.7\%) were males. A female predominance with a female-to-male ratio of 1.52: 1 was noted. 


\section{Age}

The age of patients ranged from 9 to 72 years. There were 26 and 22 patients each in the age groups of 21 - 30 years and 31 - 40 years, constituting $21.8 \%$ and $18.2 \%$ respectively. There were 1 patient $(0.8 \%)$ each in the age group below 10 years and above 70 years.

\section{Presenting Complaints}

The majority of patients in this study had multiple presenting complaints; 92 of them presented with complaints of skin lesions (96.7\%), which in most cases were also associated with pruritus $(76 \%)$. Fever formed the presenting complaint in 8 patients $(6.6 \%)$. The mucosal lesions constituted the presenting complaint in 14\%. These are indicated in Table 1.

\begin{tabular}{|c|c|c|}
\hline Presenting Complaints & Frequency & Percentage \\
\hline Skin Lesions & 117 & 96.7 \\
\hline Pruritus & 92 & 76.0 \\
\hline Fever & 8 & 6.6 \\
\hline Others & 17 & 14.0 \\
\hline \multicolumn{2}{|c|}{ Table 1. Presenting Complaints } \\
\hline
\end{tabular}

\section{Drug Groups}

Most of the patients in this study had taken drugs from multiple groups. The major groups of drugs taken by patients were NSAIDs and other analgesics in 56 patients (46.3\%), antibiotics in 48 patients (39.7\%), anticonvulsants in 42 patients (34.7\%) and GI drugs in 40 patients (33.1\%).

\section{Individual Drugs}

The predominant drug used from each drug group was noted. Out of 48 patients who had taken antibiotics, 24 patients had taken penicillins $(19.8 \%)$ followed by cephalosporins in 8 patients $(6.6 \%)$. There were 2 patients $(1.7 \%)$ who had taken dapsone. Among the anticonvulsants, 27 patients $(22.3 \%)$ had taken phenytoin followed by carbamazepine in 8 patients (6.6\%). In the case of NSAIDs and other analgesics, 22 patients $(18.2 \%)$ gave history of use of paracetamol and 10 patients $(8.3 \%)$ with history of use of diclofenac. There were 4 patients $(3.3 \%)$ with history of use of hypouricemics, all of whom had taken allopurinol.

The oral route was the major mode of drug administration in 115 patients (95\%). There were 4 patients (3.3\%) with parenteral route of drug administration and there were 2 patients $(1.7 \%)$ with both routes. This is presented in Table 7 and Figure 8.

\section{Time for Reactions}

59 patients $(48.8 \%)$ had developed reaction within 3 days of administration of the drug. The next most common time period was 8 - 14 days observed in 18 patients $(14.9 \%)$. There were 5 patients (4.2\%), who developed the reaction after 4 weeks of taking the drug. In 6 patients (5\%), the exact time period could not be calculated as the suspected drugs were taken by the patients at different points of time.

\section{Family History}

117 patients $(96.7 \%)$ did not have a family history of drug reactions. There were 4 patients $(3.3 \%)$, who had a family history of drug reactions.

\section{General Examination}

Lymphadenopathy was found in 16 patients (13.2\%) and 11 patients (9.1\%) had pallor. There were 7 patients (5.8\%) with bilateral pedal oedema and 2 patients $(1.6 \%)$ had clinically detectable jaundice in the form of icterus.

\section{Skin Lesions}

Erythematous macules, papules and small plaques were noticed in 68 patients (56.2\%). The weals and swellings in the skin with involvement of subcutaneous tissue were observed in 43 patients (36.4\%); 17 patients (14\%) had charred appearing skin lesions with majority of them having associated vesicles, bullae and erosions. Generalised erythema and scaling of body was noted in 4 patients (3.3\%). There was 1 patient $(0.8 \%)$ with purpuric lesions in the lower limb.

\section{Mucosal Lesions}

43 patients (35.5\%) had associated mucosal lesions with majority having involvement of more than one mucosal site. Oral erosions and conjunctival congestion were found in 31 patients each (72.1\%); 13 patients (30.2\%) had erosions of genital mucosa also.

\section{Investigations}

In this study, 35 patients (28.9\%) had evidence of anaemia as evidenced by low haemoglobin levels.

There was no abnormality in the total white cell count in 110 patients $(90.9 \%) ; 3$ patients $(2.5 \%)$ had evidence of leucopenia, while 8 patients $(6.6 \%)$ had elevated leucocyte count.

The eosinophil count was elevated in 33 patients (27.3\%). Also, there were $7(5.8 \%)$ patients with raised neutrophil counts and 1 patient $(0.8 \%)$ with raised lymphocyte levels.

The abnormalities in liver function tests were observed in 31 patients (25.6\%) and all the patients had elevated transaminases. Of these, 2 patients $(1.7 \%)$ also had hyperbilirubinaemia and 4 patients (3.3\%) had low albumin levels.

Skin biopsy was done in 1 patient $(0.8 \%)$, which showed features of chronic dermatitis. Clinically, this was a case of bleomycin-induced flagellate pigmentation.

Blood culture was done in 4 patients $(3.3 \%)$, who were suspected cases of septicaemia and 2 out of them (50\%) had a positive blood culture yielding Staphylococcus aureus.

Patch test was done in 39 patients (32.2\%) and a positive test result was obtained in 12 cases $(9.9 \%)$.

The patch test was mainly done with the following drug groups: Anticonvulsants in 16 patients (41.02\%), antibiotics in 10 patients $(25.64 \%)$ and NSAIDs in 11 patients $(28.2 \%)$. In 2 patients $(5.1 \%)$, patch testing was done with multiple drugs. In 16 patients tested with anticonvulsants, positive test result was obtained in 4 patients $(25 \%)$ with phenytoin producing maximum positive results. A positive test result was obtained in 3 out of 10 patients tested with antibiotics, majority with penicillins. While NSAIDs gave a positive result in 5 out of 11 patients tested $(45.5 \%)$ with paracetamol producing maximum results, but none of the patients tested with multiple drugs gave positive results. The data is represented in the following Table 2 . 


\begin{tabular}{|c|c|c|c|c|c|}
\hline $\begin{array}{c}\text { Drug } \\
\text { Tested }\end{array}$ & $\begin{array}{c}\text { Frequ- } \\
\text { ency }\end{array}$ & $\begin{array}{c}\text { \% } \\
\text { Tested }\end{array}$ & $\begin{array}{c}\text { Positive } \\
\text { Result }\end{array}$ & $\begin{array}{c}\text { \% of } \\
\text { Positive } \\
\text { Result }\end{array}$ & $\begin{array}{c}\text { Drug with } \\
\text { Maximum } \\
\text { Positivity }\end{array}$ \\
\hline Anticonvulsants & 16 & 41.02 & 4 & 25 & Phenytoin \\
\hline Antibiotics & 10 & 25.64 & 3 & 30 & Penicillin \\
\hline NSAIDs & 11 & 28.20 & 5 & 45.5 & Paracetamol \\
\hline Multiple & 2 & 5.12 & 0 & 0 & NA \\
\hline Total & $\mathbf{3 9}$ & $\mathbf{1 0 0 . 0}$ & $\mathbf{1 2}$ & $\mathbf{3 0 . 8}$ & \\
\hline \multicolumn{6}{|r}{ Table 2. Patch Test Results with Individual Drugs } \\
\hline
\end{tabular}

\section{Final Diagnosis}

The different clinical patterns of drug reactions were observed in this study. Of these, exanthematous reactions were observed in 48 patients (39.7\%) and urticaria and angioedema in 34 patients (28.1\%). There were 18 cases $(14.9 \%)$ in the SJS-TEN complex; 9 cases $(7.4 \%)$ were diagnosed with fixed drug eruptions and 5 cases $(4.1 \%)$ were diagnosed of drug hypersensitivity syndrome after investigations. There were 4 patients (3.3\%) with erythroderma and 2 patients $(1.7 \%)$ with photosensitive drug reactions respectively; 1 patient $(0.8 \%)$ was a case of bleomycin-induced flagellate pigmentation. The observations are represented in Table 3.

\begin{tabular}{|c|c|c|c|c|c|}
\hline Diagnosis & Frequency & $\%$ & & & \\
\hline $\begin{array}{c}\text { Exanthematous } \\
\text { Reactions }\end{array}$ & 48 & 39.7 & & & \\
\hline \multirow{3}{*}{$\begin{array}{l}\text { Urticaria and } \\
\text { Angioedema }\end{array}$} & \multirow{3}{*}{34} & \multirow{3}{*}{27.1} & Urticaria & 10 & 8.3 \\
\hline & & & $\begin{array}{l}\text { Angio- } \\
\text { edema }\end{array}$ & 13 & 10.7 \\
\hline & & & $\begin{array}{l}\text { Urticaria } \\
\text { and Angio- } \\
\text { edema }\end{array}$ & 11 & 9.1 \\
\hline FDE & 9 & 7.4 & & & \\
\hline \multirow{3}{*}{$\begin{array}{l}\text { SJS-TEN } \\
\text { Complex }\end{array}$} & \multirow{3}{*}{18} & \multirow{3}{*}{14.9} & SJS & 7 & 5.8 \\
\hline & & & $\begin{array}{l}\text { SJS-TEN } \\
\text { Overlap }\end{array}$ & 3 & 2.5 \\
\hline & & & TEN & 8 & 6.6 \\
\hline $\begin{array}{c}\text { Photosensitive } \\
\text { Reactions }\end{array}$ & 2 & 1.7 & & & \\
\hline Erythroderma & 4 & 3.3 & & & \\
\hline DHS & 5 & 4.1 & & & \\
\hline Others & 1 & 0.8 & & & \\
\hline
\end{tabular}

\section{Imputed Drug Groups}

Among the various drug groups studied, the 3 major groups implicated in causing reactions were NSAIDs and other analgesics in 26 patients (21.5\%), anticonvulsants in 25 patients (20.7\%) and antibiotics in 18 patients (14.9\%). Antituberculous drugs, hypouricemics and antineoplastic drugs were implicated as causative in 2 cases $(1.6 \%)$ each. There was a single case of angioedema $(0.8 \%)$, in which an antipsychotic drug was implicated. There were also 6 cases (5\%), in which indigenous drugs were considered as causative agents. In 39 patients (32.2\%), imputability could not be attributed to a single drug.

\section{Imputed Individual Drugs}

Out of 18 patients who developed reactions to antibiotics, 7 patients (39\%) had penicillins as the incriminated drug and in 5 patients $(28 \%)$ the reaction was due to cephalosporins. There were 2 patients $(11.1 \%)$ who had reactions attributed to sulfones (Dapsone), 3 patients $(16.5 \%)$ to fluoroquinolones and 1 patient (5.5\%) to tetracyclines. In case of anticonvulsants, phenytoin could be imputed in $80 \%$ of cases and the rest (20\%) was due to carbamazepine. In case of NSAIDS and other analgesics, paracetamol accounted for 11 cases $(42.3 \%)$ followed by diclofenac in 10 cases (38.5\%). There were 1 patient (3.8\%) each attributed to coxibs, aspirin and oxicams and 2 patients (7.6\%) due to etodolac. In case of antineoplastics, there was 1 case (50\%) due to bleomycin and another (50\%) due to imatinib.

\section{Reaction Patterns and Drug Groups}

The exanthematous reactions were commonly produced by anticonvulsants in 16 patients (33.33\%) followed by antibiotics and NSAIDs contributing equally in 6 cases each (18.11\%). Most cases of urticaria and angioedema in 13 patients (38.2\%) were imputed to NSAIDs and other analgesics with the remainder 10 patients due to antibiotics (29.4\%). Of the 9 cases of FDE, NSAIDs produced reactions in 5 patients (55.55\%) and 1 patient each (11.11\%) by antibiotics and anticonvulsants. In cases of reactions in SJSTEN complex, anticonvulsants produced reactions in 4 patients $(22.22 \%)$ with the remainder by NSAIDs and allopurinol. DHS was noted to be caused by anticonvulsants in 4 patients $(80 \%)$ and by dapsone in 1 patient (20\%). There were 2 cases (50\%) of ATT-induced erythroderma and 1 case each $(25 \%)$ due to psychiatry drugs and indigenous drugs. This is shown in Table 4.

\begin{tabular}{|c|c|c|c|c|c|c|c|c|c|}
\hline Diagnosis & 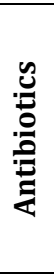 & 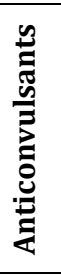 & 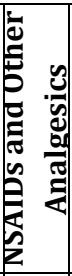 & 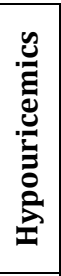 & 乩 & 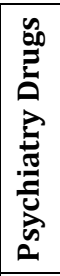 & 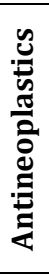 & 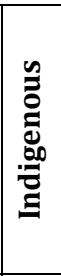 & 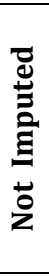 \\
\hline $\begin{array}{l}\text { Exanthematous } \\
\text { Eruptions }\end{array}$ & 6 & 16 & 6 & 0 & 0 & 0 & 0 & 3 & 17 \\
\hline Urticaria & 5 & 0 & 3 & 0 & 0 & 0 & 0 & 0 & 2 \\
\hline Angioedema & 1 & 0 & 6 & 0 & 0 & 0 & 0 & 1 & 5 \\
\hline $\begin{array}{l}\text { Urticaria and } \\
\text { Angioedema }\end{array}$ & 4 & 0 & 4 & 0 & 0 & 0 & 0 & 1 & 2 \\
\hline FDE & 1 & 1 & 5 & 0 & 0 & 0 & 0 & 0 & 2 \\
\hline SJS & 0 & 1 & 1 & 0 & 0 & 0 & 0 & 0 & 5 \\
\hline SJS-TEN & 0 & 0 & 0 & 1 & 0 & 0 & 0 & 0 & 2 \\
\hline TEN & 0 & 3 & 0 & 1 & 0 & 0 & 0 & 0 & 4 \\
\hline $\begin{array}{c}\text { Photosensitive } \\
\text { Reactions }\end{array}$ & 0 & 0 & 1 & 0 & 0 & 0 & 0 & 1 & 0 \\
\hline Erythroderma & 0 & 0 & 0 & 0 & 2 & 1 & 1 & 0 & 0 \\
\hline DHS & 1 & 4 & 0 & 0 & 0 & 0 & 0 & 0 & 0 \\
\hline Others & 0 & 0 & 0 & 0 & 0 & 0 & 1 & 0 & 0 \\
\hline Total & 18 & 25 & 26 & 2 & 2 & 1 & 2 & 6 & 39 \\
\hline
\end{tabular}




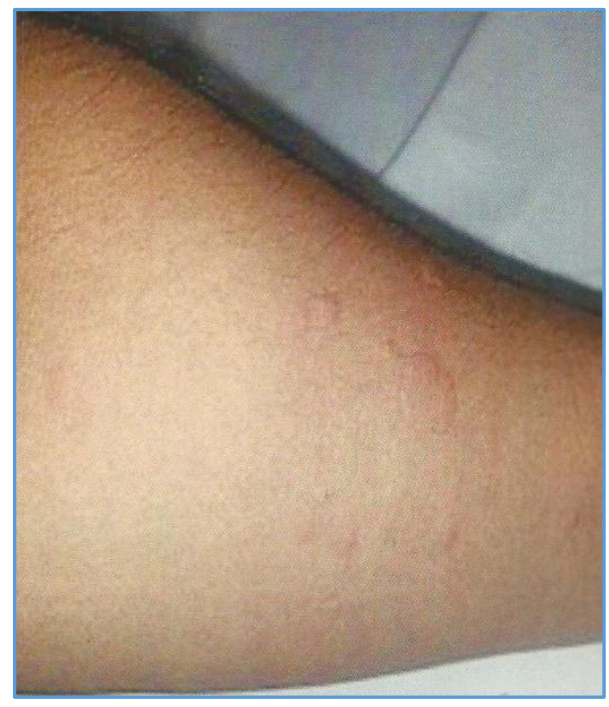

Image 1. Urticarial lesions

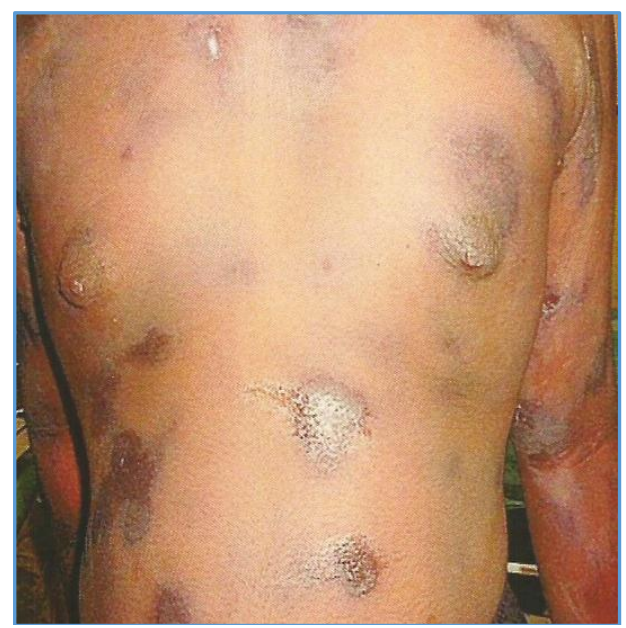

Image 2. Generalised Bullous Fixed Drug Eruptions

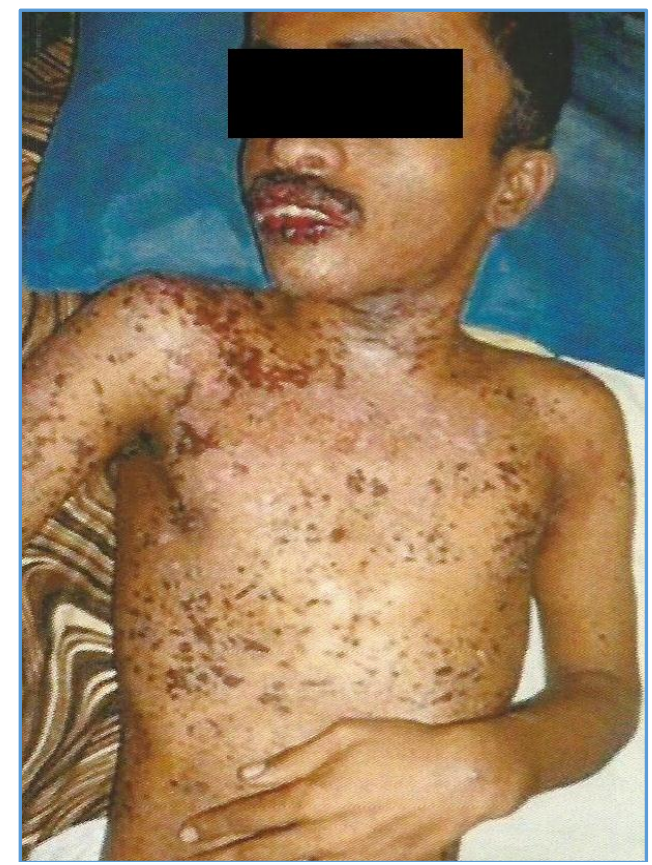

Image 3. Skin and mucosal lesions of toxic epidermal necrolysis

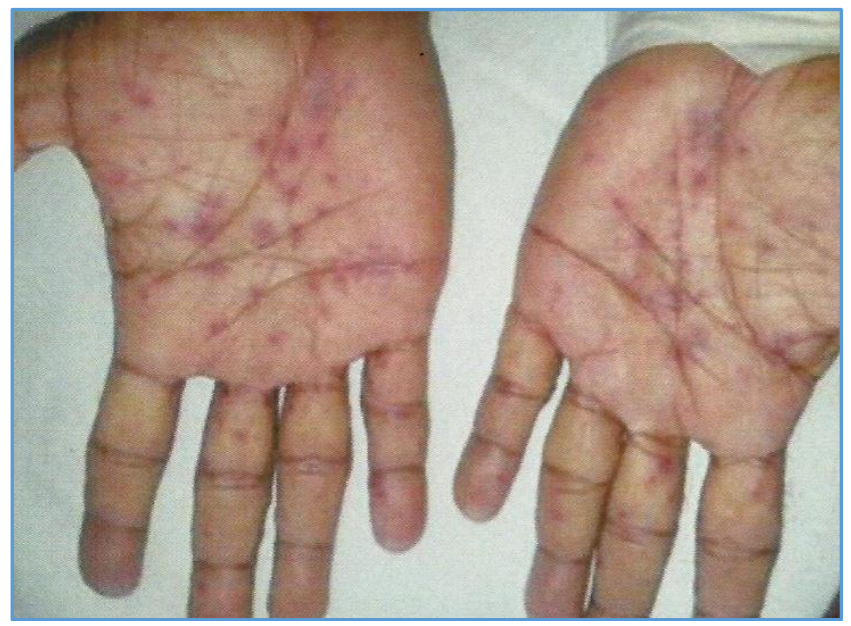

Image 4. Palmar lesions in SJS-TEN Complex

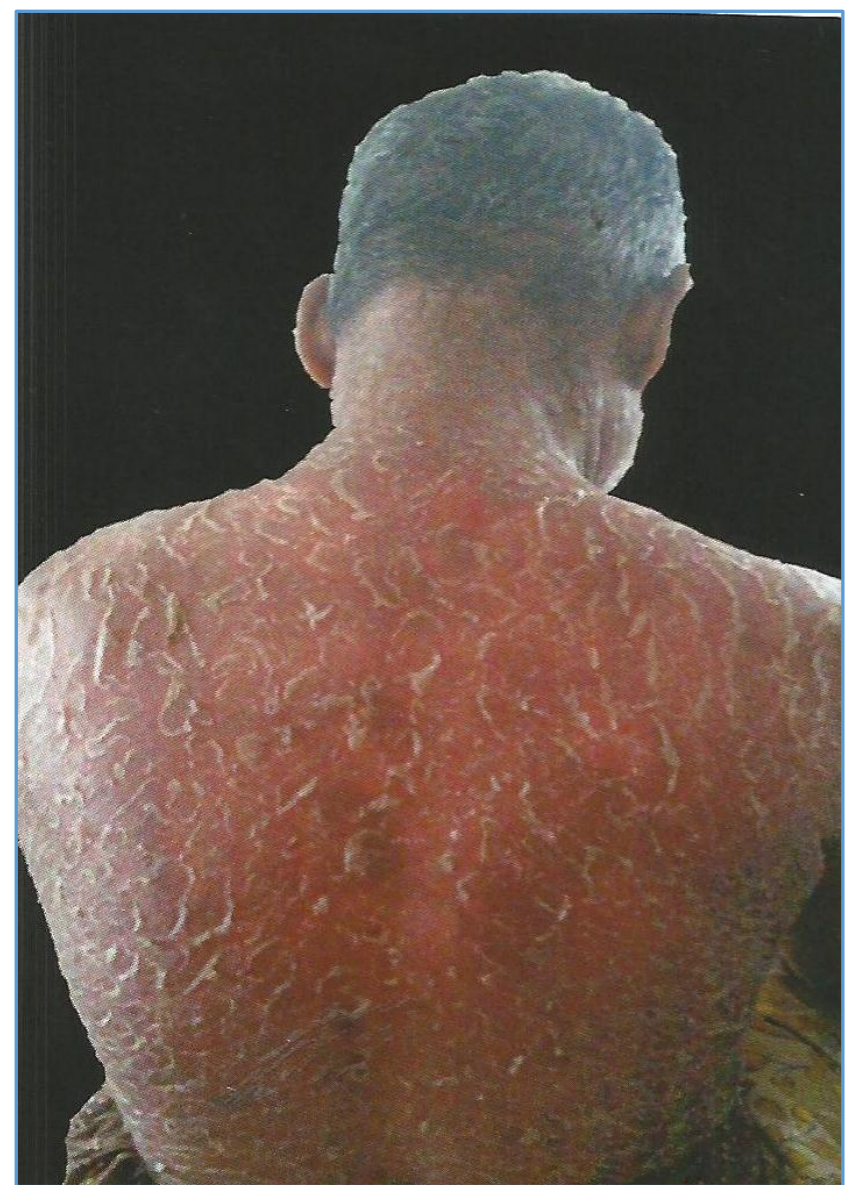

Image 5. Exfoliative Dermatitis induced by Phenytoin Image 6. Consent form

\section{DISCUSSION}

A female preponderance was noticed in this study, the female-to-male ratio being 1.52: 1. This was similar to studies by Akpinar F in Turkey and Thappa DM in Pondicherry. 4,5 But a 6-month study by Albala et al in France showed a male preponderance. ${ }^{6}$

Most of the patients were in the age group between 21 30 years $(21.5 \%)$ followed by $31-40$ years $(18.2 \%)$. A similar observation was made by Sushma et al in a study at Bangalore and Hiware et al at Nagpur.7,8 This may be due to the increased use of drugs, especially antibiotics and NSAIDS in this age group. 
In this study, $15.7 \%$ of patients gave a previous history of drug reactions. This observation is in concordance with study done in Oman, in which $18 \%$ of patients gave history of previous drug reactions. ${ }^{9}$

In $54.5 \%$ of individuals there was history of other systemic illnesses, the most common being atopy in $16.5 \%$ which is similar to studies by Al Raaie et al and Borch et al.9,10

The most significant finding in general examination was lymphadenopathy in 16 patients $(13.2 \%)$ with all cases of drug hypersensitivity syndrome showing significant lymphadenopathy. But a six-year study in Thailand on DHS showed lymphadenopathy in only $22.2 \%$ of cases. ${ }^{11}$ Fever was noticed in $9.9 \%$ of cases, of which $41.6 \%$ comprised cases of drug hypersensitivity syndrome in which all cases had associated fever. This is similar to study on DHS in Thailand, in which $88.9 \%$ of cases had fever. ${ }^{11}$ Two cases of toxic epidermal necrolysis also had associated fever.

On investigations eosinophilia was noticed in $27.3 \%$ of cases, which is similar to a study by Borch et al where peripheral blood eosinophilia was noticed in $36-75 \%$ of cases of ADR. ${ }^{10}$ In this study, peripheral blood eosinophilia was maximally noticed in cases of exanthematous reactions (63.6\%), while severe drug reactions like SJS/TEN and DHS did not show significant raised eosinophils. This observation is contrary to most of the studies, as higher counts of eosinophils are commonly observed with severe reactions making it a useful prognostic test. ${ }^{11}$ There was a single case of pancytopenia, which was a case of drug hypersensitivity syndrome induced by phenytoin. Leucopenia and thrombocytopenia were noticed in $1.6 \%$ and $2.4 \%$ of cases respectively, but it was not associated with bleeding manifestations.

Hepatic complications were noticed in $25.6 \%$ of cases. This is in concordance with a study in Thailand, in which more than $90 \%$ had evidence of hepatic dysfunction. ${ }^{11} \mathrm{~A}$ study of SJS/TEN showed liver abnormalities in $50 \%$ of cases. ${ }^{12}$

A patch test was done 6 weeks after subsidence of lesions in $32.2 \%$ of cases excluding the severe forms of drug reactions. Of this, $30.7 \%$ of cases showed a positive test result. In a study in India, $42.85 \%$ of patients showed a positive result in patch test. ${ }^{13}$ This variation in results may be due to differences in the type of reactions and tested drugs in other series.

The 3 most common reaction patterns observed in our study were exanthematous reactions $(39.7 \%)$ followed by urticaria/angioedema (28.1\%) and SJS/TEN complex (14.9\%). A similar observation was noticed in a study of drug reactions at Singapore. ${ }^{7}$ While a study by Al Raaie et al found urticaria followed by FDE to be predominant reaction patterns. ${ }^{9}$ This variation in the reaction patterns may be due to the different patterns of drug usage and the different ethnic group characteristics. SJS-TEN complex made up for $14.9 \%$ of cases similar to a study in India of 90 patients of cutaneous ADR, where SJS-TEN complex was observed in 17 patients (18.8\%). ${ }^{5}$ The incidence of SJS/TEN is estimated at 2 to 3 cases/million population/year in Europe and the US.14 These indicate that the number of these cases vary from region to region. Severe cutaneous adverse reactions made up to $38.8 \%$ of cases similar to the study at Singapore. ${ }^{7}$ These high rates of SCAR observed in our study may be due to the fact that most of these cases were referred from resourcepoor peripheral centres.

The commonest offending drug group in this study was NSAIDs and other analgesics (21.5\%) followed by anticonvulsants $(20.7 \%)$ and antibiotics $(14.9 \%)$. This was found to be the three major drug groups implicated in most studies. ${ }^{8,15}$ But in most studies, antimicrobials were the most common drugs in the causation of ADRs. 7,4

The observation of penicillins (39\%) followed by cephalosporins (28\%) as the commonest antibiotics conforms with most of the previous studies except the study at St. John's Medical College, Bangalore, which reported highest incidence with fluoroquinolones. ${ }^{16}$

In contrary to the common observation of carbamazepine being the commonest drug causing ADR among anticonvulsants, phenytoin was found to be more commonly attributed in ADR in this study. This may be due to the increasing awareness among physicians and neurologists regarding the higher incidence of carbamazepine-induced ADR. ${ }^{16,15}$

Among NSAIDs, the maximum numbers of cases were due to paracetamol (42.3\%) followed by diclofenac (38.5\%). A similar observation was made in a South Indian study on ADR, but a study of 106 patients in Turkey showed increased incidence due to naproxen over others. ${ }^{4,8}$

The type of reactions to different drugs also showed variation in this study. Exanthematous reactions were most commonly due to anticonvulsants (33.33\%) followed by antibiotics (18.1\%). This finding shows discordance with many previous studies, which report an increased incidence of exanthema to antibiotics rather than anticonvulsants. ${ }^{15}$ Urticarial reactions were most commonly caused by NSAIDs and other analgesics (38.2\%). These results were similar to an Indian study, where NSAIDs caused maximum number of urticaria. ${ }^{8}$

In this study, NSAIDs formed the largest group producing FDE. In a study by Pasricha in 1987, tetracyclines were responsible for the maximum number of cases. ${ }^{17}$ In a study by Gupta in 2003, cotrimoxazole accounted for the maximum number of cases. ${ }^{18}$ However, this study shows concordance with a latest study on ADR in 2012, which reports increasing incidence of FDE with NSAIDs. ${ }^{19}$ This changing trend is thought to reflect upon the differences in drug usage over the years. In this study, no correlation between the site of predilection and offending drug was observed, though a study of 158 cases of FDE in Medical College, Kottayam observed a consistent pattern. ${ }^{20}$ This may be due to the relatively smaller sample size in this study.

In most cases SJS-TEN complex were caused by anticonvulsants $(22.22 \%)$ with the rest being caused by allopurinol and NSAIDs. This observation is similar to the study by Sharma et al, in which anticonvulsants caused maximum number of cases. ${ }^{12}$

Anticonvulsants (80\%) formed the major drug group causative for DHS in this study with the rest $20 \%$ being caused by dapsone. This is in agreement with a large case series of DHS in Thailand, where maximum number of cases were due to phenytoin. ${ }^{11}$ 


\section{CONCLUSION}

This prospective descriptive study on cutaneous adverse drug reactions in 121 cases showed the commonest pattern of drug reaction being exanthematic type followed by urticaria/angioedema and SJS/TEN complex. The commonest offending drug group was NSAIDS, in which paracetamol and diclofenac were the commonest individual drugs imputed followed by anticonvulsants and antibiotics. Penicillins and cephalosporins were the commonest antibiotics responsible. The previously implicated carbamazepine as the commonest cause for severe cutaneous adverse reactions has been taken over by phenytoin as observed in this study. The in vivo patch test using the suspected offending drug as the antigen was positive in $30.7 \%$ of the tested cases indicating its role as an adjunct to clinical diagnosis as in a few earlier studies.

\section{REFERENCES}

[1] Sehgal VN, Jain S, Bhattacharya SN. Cutaneous drug reactions. J Eur Acad Dermatol Venereol 1993;2:28195.

[2] Breathnach SM. Drug Reactions. In: Burns T, Breathnach S, Cox N, et al. eds. Rook's textbook of dermatology. $8^{\text {th }}$ edn. Vol. 4. West Sussex: Blackwell Publishing Ltd., 2010;75:1-44.

[3] Revuz J, Allanore LV. Drug reactions. In: Bolognia JL, Jorizzo JL, Schaffer JV. eds. Dermatology. $3^{\text {rd }}$ edn. Vol. 1. Philadelphia: Mosby Elsevier 2013:335-56.

[4] Akpinar F, Dervis E. Drug eruptions: an 8-year study including 106 inpatients at a dermatology clinic in Turkey. Indian J Dermatol 2012;57(3):194-8.

[5] Pudukadan D, Thappa DM. Adverse cutaneous drug reactions: clinical pattern and causative agents in a tertiary care center in South India. Indian J Dermatol Venereol Leprol 2004;70(1):20-4.

[6] Fiszenson-Albala F, Auzerie V, Mahe E, et al. Epidemiology and Health Services Research. A 6month prospective survey of cutaneous drug reactions in a hospital setting. $\mathrm{Br} J$ Dermatol 2003;149(5):1018-22.

[7] Hiware S, Shrivastava M, Mishra D, et al. Evaluation of cutaneous drug reactions in patients visiting outpatient departments of Indira Gandhi Government Medical College and Hospital (IGGMC and H), Nagpur. Indian J Dermatol 2013;58(1):18-21.
[8] Sushma M, Noel MV, Ritika MC, et al. Cutaneous adverse drug reactions: a 9-year study from a South Indian hospital. Pharmacoepidemiol Drug Saf 2005;14(8):567-70.

[9] Al-Raaie F, Banodkar DD. Epidemiological study of cutaneous adverse drug reactions in Oman. Oman Med J 2008;23(1):21-7.

[10] Borch JE, Andersen KE, Bindslev-Jensen C. The prevalence of acute cutaneous drug reactions in a Scandinavian university hospital. Acta Derm Venereol 2006;86(6):518-22.

[11] Wongkitisophon P, Chanprapaph K, RattanaKaemakorn $\mathrm{P}$, et al. Six-year retrospective review of drug reaction with eosinophilia and systemic symptoms. Acta Derm Venereol 2012;92(2):200-5.

[12] Sharma VK, Sethuraman G, Minz A. Stevens Johnson syndrome (SJS), toxic epidermal necrolysis (TEN) and SJS-TEN overlap: a retrospective study of causative drugs and clinical outcome. Indian J Dermatol Venereol Leprol 2008;74(3):238-40.

[13] Balachandran C, Shenoi SD, Sarkar D, et al. Patch tests in adverse cutaneous drug reaction. Indian J Dermatol Venereol Leprol 2002;68(1):13-5.

[14] Fritsch PO, Sidoroff A. Drug-Induced Stevens-Johnson syndrome/toxic epidermal necrolysis. Am J Clin Dermatol 2000;1(6):349-60.

[15] Ding WY, Lee CK, Choon SE. Cutaneous adverse drug reactions seen in a tertiary hospital in Johor, Malaysia. Int J Dermatol 2010;49(7):834-41.

[16] Huang HY, Luo XQ, Chan LS, et al. Cutaneous adverse drug reactions in a hospital-based Chinese population. Clin Exp Dermatol 2011;36(2):135-41.

[17] Pasricha JS. Drugs causing fixed eruptions. Br J Dermatol 1979;100(2):183-5.

[18] Gupta R. Drugs causing fixed drug eruptions: confirmed by provocation tests. Indian J Dermatol Venereol Leprol 2003;69(2):120-1.

[19] Choon SE, Lai NM. An epidemiological and clinical analysis of cutaneous adverse drug reactions seen in a tertiary hospital in Johor, Malaysia. Indian J Dermatol Venereol Leprol 2012;78(6):734-9.

[20] Thankappan TP, Zachariah J. Drug-specific clinical pattern in fixed drug eruptions. Int J Dermatol 1991;30(12):867-70. 